\title{
Design, Maintenance, and the Menstruating Body
}

\section{Sarah Fox}

Human Centered Design \& Engineering

University of Washington

sefox@uw.edu

\section{Abstract}

In this submission, I discuss my research on the maintenance of public restrooms and, more specifically, the distribution and stratification of menstrual resources throughout the city of Seattle. Through interviews, technology development, and field engagements, I show how digital artifacts-such as those connected to the Internet of Things-structure experiences of hygiene access and help expose the socioeconomic logics undergirding infrastructures of public life. I use design interventions to further examine the role of technology to cultivate and

Permission to make digital or hard copies of part or all of this work for personal or classroom use is granted without fee provided that copies are not made or distributed for profit or commercial advantage and that copies bear this notice and the full citation on the first page.

Copyrights for third-party components of this work must be honored. For all other uses, contact the Owner/Author.

DIS'18 Companion, June 9-13, 2018, Hong Kong

(C) 2018 Copyright is held by the owner/author(s).

ACM ISBN 978-1-4503-5631-2/18/06.

https://doi.org/10.1145/3197391.3205386 maintain collective responsibility and forms of participatory infrastructure.

\section{Author Keywords}

Feminism; infrastructure; maintenance; restrooms.

\section{ACM Classification Keywords}

K.4.0 Computers in Society: general.

\section{Introduction}

In this submission, I discuss my study of menstrual resource development and the cultural politics of high tech interventions in daily life, with particular focus on the entanglements of data, technologies, and governance. Specifically, I examine technologies linked to the Internet of Things (IoT) - or, ubiquitous networked objects imbued with computational capacity - and explore how these "self-governing machines" shape access to public resources. Drawing on interviews and observations, I redesigned menstrual hygiene dispensers placed in public settings by outfitting them with networked sensor inserts so that the product levels might be more easily stocked and shared.

Inspired by science and technology studies scholars Michelle Murphy $[6,7]$ and Maria Puig de la Bellacasa [1], my technical designs and ethnographic 
investigations explore the politics of care and maintenance work to reveal the stratification of resources across socio-spatial bounds, with the goal of collaboratively reimagining and redesigning technological and infrastructural conditions.

\section{Background}

Over the last several years, there has been a flurry of interest in the long-hushed topic of menstruation-from a legislative turn that includes local, state and federal policy initiatives calling for free and ready access to hygiene products to the formation of over a dozen startups with tens of millions in venture capital backing. Alongside these efforts, exist longer running programs including the installation and maintenance of dispensers in public restrooms and efforts of activists who collect and redistribute menstrual resources to those unable to afford them. My interest in menstruation as a site of technological intervention is rooted in these existing histories of activism and material production.

Maintenance Regimes and Differential Care In focusing on forms of maintenance practice in and around public restrooms, I follow a recent strand of work within and just beyond the DIS community concerned with designing for repair or ongoing maintenance. Over innovation or development, scholars such as Lara Houston and Steve Jackson position breakdown, dissolution, and change as key concerns of technology scholarship $[4,5]$. Underlying this focus on maintenance is a commitment to thinking of design as one moment within the long-term lifecycle of computational goods. Important for my work, Jérôme Denis and David Pontille enumerate the dimensions of practice that make up repair regimes, "the distribution of maintenance practices, the kinds of objects that are enacted through them, and the ecology of the visible and invisible at play in the various ways maintenance work is accomplished and organized." [2:13].

Expanding on this notion of regimes of repair, my dissertation work also draws on Science and Technology Studies (STS) scholars who describe a politics of care $[1,6,7]$. Rather than seeing care as inherently oriented toward good, Michelle Murphy urges scholars to critically engage with how care labor may be entangled in non-innocent hegemonic structures of capitalism, racial privilege, and patriarchy-a move signifying a "generatively unsettling" [7:722]. In what follows, I work through the lens of unsettling by reckoning with the ways in which maintenance and access to hygiene resources stratify across a single city.

\section{Work in Progress}

Responding to and building on this scholarship, I drew on interviews and observations with custodial professionals (at parks, community centers, and homeless shelters) and members of activist and
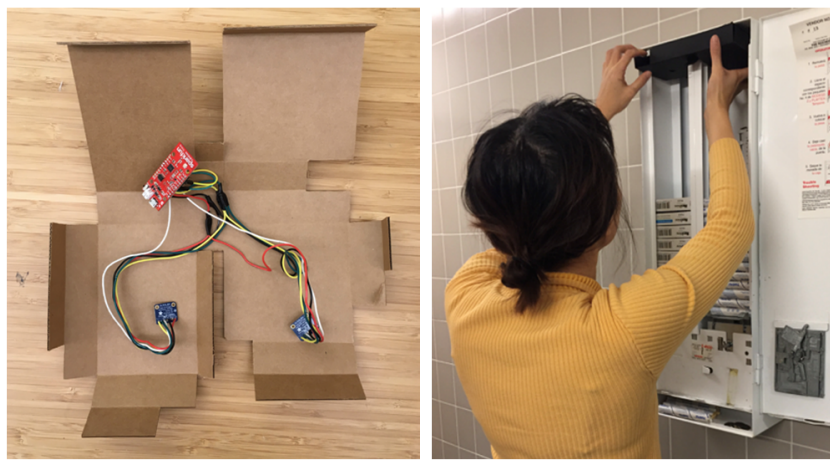

Figure 1 The IoT insert disassembled (left) and in the process of installation (right). 
advocacy organizations to modify existing menstrual hygiene dispensers. Specifically, I outfitted them with networked sensors that collect data on product levels and share that information on an online map so that dispensers might be more easily stocked and accessed by members of the public. Further, one advocacy organization used data from the dispensers to gauge the potential cost of proposed state legislation requiring all public schools to stock products, with plans to also use it as a means of tracking the program's uptake if the law is passed.

\section{IoT Development}

With this project, I contribute to recent literature exploring the potential for civic IoT devices, deployed in public space and in support of community-based initiatives [3]. By focusing attention on designing systems and services to support the work of caring labor and public resource availability, I intervene on both the sites where IoT devices are typically placed (public, rather than private spaces) and for whom and to what end these systems are meant to support. I also complement the critical work of Murphy and de la Bellacasa, by not only critiquing the disproportionate effect of particular forms of resource allocation, but also reckoning through design with the technological and political structures shaping access.

\section{Partial Responses}

I later used this discussion and design experimentation on public services and care to develop a series of collaborative workshops meant to further reimagine the infrastructure of access for people with limited resources. During these meetings, several groups of lawmakers, activists, and community members worked together to investigate limitations to current products, services and systems in ways that were meant to reveal paths to providing more ready and reliable menstrual hygiene resources. The concepts that emerged from these workshops ranged from policy to product to infrastructural interventions-all described in a resulting "Catalog of Partial Things." One such idea detailed a network of Little Menstrual Boxes (a la Little Free Libraries) that would hold hygiene products, along with books and information on local health resources. Another group imagined a suite of bills to be introduced to the state legislature, requiring products in schools and incentivizing business owners to do the same through tax credits.

Rather than a static record of these conversations or documentation of the discrete products, the booklet itself is a research object. Sent to other stakeholders unable to attend the workshops in person, the catalog builds upon these brief encounters by enrolling others to comment, edit, revise and further develop the ideas Taken together, the workshop series and the dynamic catalog offer insight into what feminist anthropologist Marilyn Strathern [8] calls partial connections - or, the
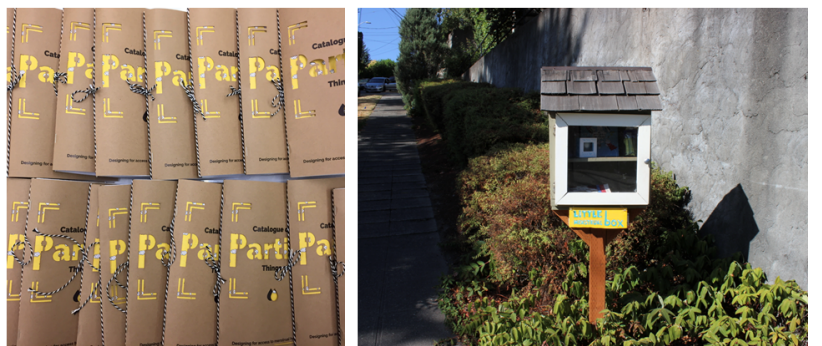

Figure 2 A set of Catalogues ready to be circulated (left) and a proof-of-concept prototype of the Little Menstrual Box (right; an idea described during the first workshop). 
partnerships constituted across difference - by experimenting with the scale, form, and complexity of located interventions.

\section{Conclusion}

My research reveals what might appear mundane or instrumental (menstrual products, their public distribution, and the care labor that sustains them) as integral to material and social innovation. This view advances discussions in technology studies critiquing the tendency of design methods to construct a universal image of "the user," or a top-down view of who counts. By looking at the margins of envisioned IoT usage, my work pushes back on this inclination to propose single technological solutions for all, to instead offer partial responses (both in the variety of ideas put forth and the methods taken up). Together these contributions provide conceptual scaffolding toward efforts to design adaptable, community supported, and collaboratively maintained infrastructures.

\section{Acknowledgements}

This work was made possible by NSF grants 1453329 , 1423074 , and 1523579.

\section{References}

1. María Puig de la Bellacasa. 2017. Matters of Care: Speculative Ethics in More Than Human Worlds. University of Minnesota Press.
2. Jérôme Denis and David Pontille. 2017. Beyond breakdown: Exploring Regimes of Maintenance. continent. 6, 1: 13-17.

3. Carl DiSalvo and Tom Jenkins. 2017. Fruit Are Heavy: A Prototype Public IoT System to Support Urban Foraging. Proceedings of the 2017 Conference on Designing Interactive Systems, ACM, 541-553.

4. Lara Houston, Steven J. Jackson, Daniela K. Rosner, Syed Ishtiaque Ahmed, Meg Young, and Laewoo Kang. 2016. Values in Repair. Proceedings of the 2016 CHI Conference on Human Factors in Computing Systems, ACM, 1403-1414.

5. Steven J. Jackson. 2013. Rethinking Repair. In P. Boczkowski, K. Foot, and T. Gillespie, eds., Media Meets Technology. MIT Press.

6. Michelle Murphy. 2012. Seizing the Means of Reproduction: Entanglements of Feminism, Health, and Technoscience. Duke University Press.

7. Michelle Murphy. 2015. Unsettling care: Troubling transnational itineraries of care in feminist health practices. Social Studies of Science 45, 5: 717-737.

8. Marilyn Strathern. 2004. Partial Connections. Rowman Altamira. 